\title{
KHÁI NIỆM VÀ ĐỀ XUẤT TIÊU CHÍ XÁC ĐỊNH CHUYẾN GIA KHOA HỌC VÀ CÔNG NGHỆ NGÀNH TÀI NGUYÊN VÀ MÔI TRƯỜNG
}

\author{
NGUYẼ̃N MẠNH DŨNG(1), LƯU TH! THUÝ NGỌC(1) \\ TRƯO'NG TH! HOA் (2) \\ ${ }^{(1)}$ Viện Khoa học Đo đạc và Bản đồ \\ ${ }^{(2)} V u ̣$ Khoa học và Công nghệ - Bộ Tài nguyên và Môi trường
}

\section{Tóm tắt:}

Bài viết giới thiệu kết quả của nội dung nghiên cứu thuộc đề tài nghiên cứu khoa học và công nghệ "Nghiên cứu cơ sở khoa học xây dựng hệ thống tiêu chí xác định chuyên gia, cán bộ khoa học và công nghệ trong các lĩnh vực tài nguyên và môi trường" do Viện Khoa học Đo đạc và Bản đồ chủ trì.

\section{Mở đầu}

Đề tài nghiên cứu khoa học và công nghệ cấp cơ sở năm 2017 "Nghiên cứu cơ' sở khoa học xây dựng hệ thống tiêu chí xác định chuyên gia, cán bộ khoa học và công nghệ trong các lĩnh vực tài nguyên và môi trường" do Viện Khoa học Đo đạc và Bản đồ chủ trì thực hiện. Mục tiêu của Đề tài nhằm làm rõ cơ sở lý luận về hệ thống tiêu chí xác định chuyên gia, cán bộ khoa học và công nghệ $(\mathrm{KH \& CN})$ trong các lĩnh vực tài nguyên và môi trường; Xây dựng bộ tiêu chí xác định, lựa chọn chuyên gia, cán bộ khoa học và công nghệ trong các lĩnh vực tài nguyên và môi trường (TN\&MT). Một trong những nội dung nghiên cứu quan trọng là đưa ra khái niệm về chuyên gia, chuyên gia khoa học và công nghệ và đưa ra các tiêu chí lựa chọn, xác định chuyên gia khoa học và công nghệ trong ngành tài nguyên và môi trường. Một trong những hạn chế hiện nay trong việc xét chọn, tuyển chọn các nhiệm vụ khoa học và công nghệ cấp Bộ là chưa có hệ thống cơ sở dữ liệu (CSDL) về chuyên gia khoa học và công nghệ ngành tài nguyên và môi trường. Trong khuôn khổ giới hạn của bài viết trên Tạp chí, chúng tôi chỉ trình bày một số thông tin cơ bản về xác định khái niệm và tiêu chí lựa chọn chuyên gia $K H \& C N$ ngành tài nguyên và môi trường - một trong những kết quả chính của nghiên cứu nêu trên.

\section{Các khái niệm liên quan}

Trong quá trình nghiên cứu đề tài, có rất nhiều khái niệm và cách hiểu về chuyên gia do cách tiếp cận khác nhau. Trong Bách khoa toàn thư mở Wikipedia chuyên gia được định nghĩa như sau "Chuyên gia là thuật ngữ chỉ về những người người được đào tạo theo hướng chuyên sâu có kinh nghiệm thực hành công việc và có kỹ năng thực tiễn, lý luận chuyên sâu về một lĩnh vực cư thể hoặc có hiểu biết vượt trội so với mặt bằng kiến thức chung" [4]. Trong Đại Từ điển tiếng Việt, chuyên gia được định nghĩa là "người đi sâu nghiên cứu một lĩnh vực chuyên môn nào đó và đã có hiểu biết sâu sắc về lĩnh vực chuyên môn đó" [3]. Các định nghĩa trên đều tiếp cận chuyên gia theo

\footnotetext{
Ngày nhận bài: 05/02/2018, ngày chuyển phản biện: 08/02/2018, ngày chấp nhận phản biện: 28/02/2018, ngày chấp nhận đăng: 06/3/2018
} 
hướng nghề nghiệp. Còn một hướng khác đó là tiếp cận theo hướng trí tuệ như trong tài liệu "Xây dựng đội ngũ chuyên gia và sử dụng chuyên gia" của GS Hoàng Chi Bảo cho rằng "chuyên gia là những người ưu tú nhất, nổi trội nhất, kết tinh tài năng sáng tạo của cộng đồng và xã hội, nảy sinh trong xã hội, qua chọn lọc và phân hóa mà trở thành đại biểu sáng giá nhất, tiêu biểu cho cộng đồng, cho hoạt động và đời sống của cộng đồng trên từng lĩnh vực nhất định". Như vậy, để được coi là chuyên gia, cần có điều kiện cần để trở thành chuyên gia cũng như điều kiện đủ để được gọi là một chuyên gia. Điều kiện cần của chuyên gia trước tiên là người có rất nhiều kinh nghiệm thu được từ việc thử nghiệm/thí nghiệm/thực nghiệm nhiều lần trong chuyên môn của họ. Điều kiện đủ là có khả năng tham vấn, tư vấn, hướng dẫn cho người khác về lĩnh vực đó.

Theo mục đích xác định chuyên gia KH\&CN ngành TN\&MT, chúng tôi đưa ra khái niệm về chuyên gia như sau: "Chuyên gia là thuật ngữ chỉ về những người được đào tạo theo hướng chuyên sâu có kinh nghiệm thực hành công việc và có kỹ năng thực tiễn, lý luận chuyên sâu về một lĩnh vực cụ thể hoặc có hiểu biết vượt trội so với mặt bằng kiến thức chung".

Các chuyên gia có thể tham gia trực tiếp hoặc gián tiếp (thông qua việc cho ý kiến, tham vấn) vào một công việc hay một lĩnh vực cụ thể. Một trong những đặc điểm quan trọng để nhận dạng chuyên gia so với các chuyên viên, đồng nghiệp thông thường là: kỹ năng, nghề nghiệp vượt trội đồng nghiệp; trong công việc luôn cho kết quả chính xác; tinh thông nghiệp vụ, am tường về công việc đang làm; được tổ chức có thẩm quyền thừa nhận hoặc công nhận bằng văn bản; có khả năng tư vấn thông thạo trên một vài lĩnh vực cụ thể.
Như vậy, để hiểu thế nào là chuyên gia $\mathrm{KH} \& \mathrm{CN}$ cần hiểu được khái niệm về hoạt động khoa học và công nghệ. Theo như Luật Khoa học và Công nghệ năm 2013 [1], hoạt động khoa học và công nghệ là hoạt động nghiên cứu khoa học, nghiên cứu và triển khai thực nghiệm, phát triển công nghệ, ứng dụng công nghệ, dịch vụ $\mathrm{KH \& CN}$, phát huy sáng kiến và hoạt động sáng tạo khác nhằm phát triển $\mathrm{KH} \& \mathrm{CN}$. Như vậy, chuyên gia về $\mathrm{KH} \& \mathrm{CN}$ có thể hiểu là những người có bề dày kinh nghiệm, chuyên môn vượt trội, hiểu biết sâu rộng về một lĩnh vực nào đó dựa trên cơ sở của sự đào tạo và tích lũy kinh nghiệm trong quá trình hoạt động $K H \& C N$, được xã hội và cộng đồng khoa học thừa nhận thông qua những cống hiến trong lĩnh vực hoạt động và nghề nghiệp của họ. Đặc biệt, họ là những người có đạo đức nghề nghiệp, có nhiều tâm huyết đối với sự phát triển khoa học và công nghệ của đất nước.

Cũng theo Luật Khoa học và Công nghệ năm 2013, nghiên cứu khoa học là hoạt động khám phá, phát hiện, tìm hiểu bản chất, quy luật của sự vật, hiện tượng trong tự nhiên, xã hội và tư duy; sáng tạo giải pháp nhằm ứng dụng vào thực tiễn. Trong nghiên cứu khoa học, chúng ta có chuyên gia lý thuyết gắn với nghiên cứu cơ bản và chuyên gia ứng dụng gắn với nghiên cứu ứng dụng. Khoa học vừa là chuyên ngành, thậm chí là chuyên ngành hẹp lại vừa theo cấu trúc liên ngành và đa ngành. Khoa học vừa gắn với đào tạo, chuyển những kết quả nghiên cứu, nhất là các tri thức lý thuyết và phương pháp đang được thẩm định và được thừa nhận tính chân lý của nó vào trong giảng dạy, đào tạo, lại vừa hướng tới ứng dụng trong sản xuất. Do sự liên kết và chuyển hóa này, có người vừa được coi là chuyên gia nghiên cứu phát minh vừa là chuyên gia giảng dạy, giáo dục, chuyên gia 
ứng dụng trong sản xuất và quản lý sản xuất.

Như đã trình bày ở phần trên, có nhiều cách hiểu về chuyên gia tùy vào cách tiếp cận. Tuy nhiên, việc xác định chuyên gia KH\&CN để xây dựng tiêu chí lựa chọn chuyên gia đưa vào $\mathrm{CSDL}$ chuyên gia KH\&CN ngành tài nguyên và môi trường cần dựa trên nhu cầu, mục đích xây dựng CSDL chuyên gia KH\&CN của từng lĩnh vực. Có thể xác định đối với ngành tài nguyên và môi trường (TN\&MT), việc xây dựng tiêu chí xác định, lựa chọn chuyên gia KH\&CN nhằm mục đích: thứ nhất, thiết lập được CSDL chuyên gia, hỗ trợ cho các nhà quản lý hoạt động $\mathrm{KH} \& \mathrm{CN}$ tìm kiếm chuyên gia, tiếp cận, tham vấn ý kiến các chuyên gia tham gia Hội đồng xét chọn, tuyển chọn các nhiệm vụ nghiên cứu $\mathrm{KH} \& C N$ các cấp nhằm nâng cao hiệu quả tuyển chọn các nhiệm vụ nghiên cứu $K H \& C N$ và nâng cao hiệu quả đầu tư cho $\mathrm{KH} \& \mathrm{CN}$; thứ hai, là tiền đề cho việc thúc đẩy các cán bộ nghiên cứu khoa học và công nghệ ngành TN\&MT nâng cao trình độ chuyên môn, hiểu biết và không ngừng tìm hiểu các thông tin mới về khoa học và công nghệ trên thế giới để áp dụng tại Việt Nam, nâng cao hiệu quả ứng dụng kết quả nghiên cứu, là một lực đẩy quan trọng để các cán bộ nghiên cứu $\mathrm{KH} \& \mathrm{CN}$ đứng vào đội ngũ chuyên gia $K H \& C N$ của ngành TN\&MT.

Tuy nhiên, việc lựa chọn chuyên gia không thể dựa trên định tính mà cần phải có định lượng cụ thể, có tiêu chí cụ thể trong việc xác định chuyên gia phù hợp đối với từng lĩnh vực. Đối với ngành TN\&MT, việc lựa chọn chuyên gia của 9 lĩnh vực theo Nghị định số 36/2017/NĐ-CP ngày 04 tháng 4 năm 2017 của Thủ tướng Chính phủ quy định chức năng, nhiệm vụ, quyền hạn và cơ cấu tổ chức của Bộ Tài nguyên và Môi trường [2] cần phải có tiêu chí xác định cụ thể đối với chuyên gia của từng lĩnh vực. Từ bộ tiêu chí chuyên gia KH\&CN ngành TN\&MT làm cơ sở cho việc xây dựng, cập nhật CSDL chuyên gia ngành TN\&MT theo đúng chủ trương và chỉ đạo của Bộ trưởng Bộ TN\&MT theo xu thế chung hiện này của đất nước nói chung và của các Bộ, ngành nói riêng.

\section{Tiêu chí xác định chuyên gia của} một số tổ chức KH\&CN trên thế giới và ở Việt Nam

Có nhiều cách xác định chuyên gia trên các quốc gia cũng như các tổ chức khác nhau, tùy thuộc vào mục đích xây dựng CSDL chuyên gia. Tiêu chí lựa chọn chuyên gia tham gia vào CSDL của một số tổ chức trên thế giới như sau:

Tiêu chí lựa chọn chuyên gia của Hiệp hội an toàn lương thực Châu Âu (European Food Safety Association - EFSA): việc lựa chọn chuyên gia cập nhật vào $C S D L$ cần thỏa mãn các điều kiện nhất định như: có bằng đại học hoặc tương đương trong một hoặc những lĩnh vực cụ thể; có kinh nghiệm chuyên nghiệp liên quan đến lĩnh vực cụ thể; có các công bố khoa học được xét tương đương với các báo cáo kỹ thuật liên quan tới chuyên môn...[6].

Tiêu chí lựa chọn chuyên gia của hội đồng nghiên cứu kỹ thuật và khoa học tự nhiên Canada (Natural Sciences and Engineering Research Council of Canada NSERC): có chuyên môn sâu, đại diện cho nhiều chuyên môn đa dạng; có khả năng đánh giá tốt, khả năng làm việc trong một hội đồng và kiến thức rộng về các lĩnh vực nghiên cứu mà hội đồng chịu trách nhiệm...[7].

Tiêu chí lựa chọn chuyên gia của Trung tâm Đánh giá KH\&CN Trung Quốc (National 
Centre for Science and Technology Evaluation): lựa chọn theo lĩnh vực; đã tham gia đề tài cấp quốc gia; có học hàm, học vị cao...[8].

Trong nước, đã có một số tổ chức KH\&CN xây dựng CSDL chuyên gia và có các tiêu chí riêng tùy thuộc vào mục tiêu hoạt động cụ thể. Có thể kể đến như:

CSDL chuyên gia KH\&CN của Quỹ phát triển $\mathrm{KH} \& \mathrm{CN}$ quốc gia: mục đích nhằm tuyển chọn những chuyên gia tham gia các hội đồng khoa học do Quỹ thành lập, phản biện các đề cương nghiên cứu khoa học và tư vấn cho Quỹ. Tiêu chí lựa chọn là những người có học vị tiến sĩ hoặc chức danh phó giáo sư trở lên, có kinh nghiệm và thành tích nghiên cứu xuất sắc trong 05 năm gần nhất, cụ thể là chủ trì hoặc tham gia các đề tài, dự án trong nước hoặc quốc tế; các công trình khoa học đã công bố thuộc lĩnh vực chuyên môn; kết quả nghiên cứu thuộc lĩnh vực chuyên môn được đăng ký hoặc công bố quốc tế và trong nước; kết quả nghiên cứu được áp dụng thực tiễn; giải thưởng $\mathrm{KH} \& \mathrm{CN}$.

CSDL chuyên gia KH\&CN của Viện Đánh giá Khoa học và Định giá công nghệ (Bộ $\mathrm{KH} \& C N$ ): việc xây dựng CSDL chuyên gia nhằm mục đích hỗ trợ Bộ $\mathrm{KH} \& \mathrm{CN}$ trong việc tìm kiếm các chuyên gia tham gia các hội đồng đánh giá các hoạt động $\mathrm{KH} \& \mathrm{CN}$ và tổ chức KH\&CN. Tiêu chí chuyên gia của Viện là những người có bằng tiến sĩ và có ít nhất 5 năm kinh nghiệm nghiên cứu liên tục trong lĩnh vực chuyên môn đến thời điểm được đề nghị đưa vào CSDL chuyên gia; kinh nghiệm nghiên cứu; kết quả nghiên cứu; số lượng giải thưởng $\mathrm{KH} \& \mathrm{CN}$; bằng sáng chế, giải pháp hữu ích khoa học được cấp; sách chuyên khảo; chương trình, đề tài, dự án, đè án $\mathrm{KH} \& \mathrm{CN}$ đã được nghiệm thu, hướng dẫn nghiên cứu sinh đã bảo vệ thành công luận án tiến sĩ [5].

Như vậy, qua tiêu chí lựa chọn chuyên gia của một số tổ chức $\mathrm{KH \& CN}$ trong và ngoài nước, có thể thấy tùy vào mục đích mà có những tiêu chí lựa chọn, xác định chuyên gia khác nhau. Tuy nhiên, đều có yêu cầu chung liên quan đến năng lực chuyên môn, kinh nghiệm, kết quả đăng báo/viết sách, sáng kiến/sáng chế và có những kết quả nghiên cứu nổi bật đã được công nhận...

\section{Tiêu chí xác định chuyên gia KH\&CN ngành TN\&MT}

Như đã trình bày ở trên, mục đích xây dựng bộ tiêu chí xác định chuyên gia KH\&CN ngành TN\&MT là hỗ trợ Bộ TN\&MT tìm kiếm những chuyên gia thuộc các lĩnh vực thuộc phạm vi quản lý của Bộ tham gia vào các Hội đồng tuyển chọn/xét chọn/đánh giá kết quả nghiên cứu của các nhiệm vụ $\mathrm{KH} \& \mathrm{CN}$ thuộc Bộ và nhằm nâng cao năng lực của các cán bộ nghiên cứu tại các đơn vị thuộc Bộ TN\&MT, nâng cao hiệu quả đầu tư nghiên cứu $K H \& C N$ của Bộ TN\&MT. Vấn đề Bộ TN\&MT ưu tiên, chú trọng trong thời gian tới và việc ứng dụng kết quả của các nghiên cứu $K H \& C N$, chuyển giao kết quả nghiên cứu KH\&CN. Những kết quả nghiên cứu này phải đảm bảo có khả năng ứng dụng trên thực tế, có địa chỉ ứng dụng cụ thể và có đơn vị nhận chuyển giao kết quả nghiên cứu, đặc biệt những nhiệm vụ có đăng ký sở hữu công nghiệp/sở hữu trí tuệ hoặc được công bố trên các tạp chí uy tín trên thế giới sẽ được đánh giá cao. Như vậy, từ trọng tâm của Bộ TN\&MT có thể thấy, việc xây dựng CSDL chuyên gia $\mathrm{KH} \& C N$ ngành $T N \& M T$ cần thiết có cả chuyên gia lý thuyết cũng như chuyên gia ứng dụng. Từ những mục tiêu về việc xây dựng CSDL chuyên gia $K H \& C N$ ngành TN\&MT mà chúng tôi xây dựng được tiêu 
chí xác định chuyên gia KH\&CN của ngành, tại mỗi tiêu chí có chỉ số tính điểm cụ thể, các tiêu chí xác định, lựa chọn chuyên gia KH\&CN ngành TN\&MT như sau:

\subsection{Tiêu chí 1: Tiêu chí về trình độ}

Chỉ số tính điểm tiêu chí 1: Học vị tiến sĩ, tiến sĩ khoa học; Chức danh Phó Giáo sư, Giáo sư; Nghiên cứu viên cao cấp, Kỹ sư cao cấp, Điều tra viên cao cấp tài nguyên môi trường, Dự báo viên cao cấp khí tượng thủy văn, Kiểm soát viên cao cấp khí tượng thủy văn, Giảng viên cao cấp, Chuyên viên cao cấp; Nghiên cứu viên chính, Kỹ sư chính, ngạch viên chức chính ngành tài nguyên và môi trường, giảng viên chính, chuyên viên chính.

\subsection{Tiêu chí 2: Tiêu chí kinh nghiệm}

Chỉ số tính điểm tiêu chí 2: Kinh nghiệm nghiên cứu, công tác một trong các lĩnh vực của ngành tài nguyên môi trường tính đến thời điểm đăng ký tham gia cơ sở dữ liệu chuyên gia tài nguyên môi trường

\subsection{Tiêu chí 3: Tiêu chí về năng lực chuyên môn}

Chỉ số tính điểm tiêu chí 3: Trong 5 năm liên tục tính đến thời điểm đăng ký tham gia cơ sở dữ liệu chuyên gia tài nguyên môi trường phải đáp ứng một trong các tiêu chí dưới đây: Chủ nhiệm nhiệm vụ khoa học và công nghệ cấp quốc gia/chủ biên báo cáo tổng kết đề án/dự án cấp chính phủ đã được nghiệm thu; Chủ nhiệm nhiệm vụ khoa học và công nghệ cấp bộ, cấp tỉnh/chủ biên báo cáo tổng kết đề án/dự án cấp bộ đã được nghiệm thu; Bài báo được đăng trên tạp chí khoa học chuyên ngành quốc tế có uy tín (ISI); Bài báo khoa học đã được đăng trên tạp chí khoa học chuyên ngành quốc gia thuộc Danh mục các tạp chí khoa học chuyên ngành được tính điểm công trình khoa học quy đổi khi xét công nhận đạt tiêu chuẩn chức danh Giáo sư, Phó Giáo sư do Hội đồng chức danh giáo sư Nhà nước ban hành; Hướng dẫn nghiên cứu sinh/ học viên cao học bảo vệ thành công luận án/luận văn (hướng dẫn 1, hướng dẫn 2); Tác giả sách chuyên khảo (chủ biên/đồng tác giả); Thành viên Ban chủ nhiệm chương trình khoa học và công nghệ (cấp quốc gia/cấp bộ); Sở hữu trí tuệ: Bằng độc quyền sáng chế/giải pháp hữu ích/thiết kế bố trí mạch tích hợp; Giải thưởng khoa học và công nghệ (Quốc tế/ Hồ Chí Minh/Quốc gia/Bộ Tài nguyên và Môi trường).

\subsection{Tiêu chí 4: Tiêu chí về phẩm chất đạo đức}

Chỉ số tính điểm tiêu chí 4: Không phải là người đang bị truy cứu trách nhiệm hình sự hoặc đang thi hành án hình sự; Không vi phạm các quy định tại Điều 8 về các hành vi bị cấm trong hoạt động khoa học và công nghệ, Luật khoa học và công nghệ số 29/2013/QH13; Không vi phạm các quy định về Đăng ký, lưu giữ và giao kết quả nghiên cứu khoa học và phát triển công nghệ có sử dụng ngân sách nhà nước; Không vi phạm các quy định về công tác bảo vệ bí mật nhà nước trong ngành tài nguyên và môi trường, bí mật nhà nước về khoa học và công nghệ; Không vi phạm các quy định tại Điều 4, Thông tư 10/2014/TT-BKHCN.

\section{Kết luận}

Trên đây là những thông tin trình bày quan điểm của chúng tôi về khái niệm chuyên gia $K H \& C N$ ngành TN\&MT và tiêu chí lựa chọn chuyên gia $K H \& C N$ ngành TN\&MT theo mục đích hỗ trợ Bộ TN\&MT trong việc tìm kiếm chuyên gia tham gia vào Hội đồng tư vấn xét chọn/tuyển chọn/nghiệm thu các nhiệm vụ KH\&CN thuộc 9 lĩnh vực của ngành TN\&MT và nâng cao hiệu quả đầu tư hoạt động nghiên cứu KH\&CN. Các tiêu chí đưa ra trên đây chỉ là 
bước đầu cho việc xây dựng CSDL chuyên gia KH\&CN ngành TN\&MT, mỗi tiêu chí có các chỉ tiêu cụ thể để xác định và phân loại chuyên gia theo 3 cấp độ: chuyên gia cấp 1 , chuyên gia cấp 2 , chuyên gia cấp 3 và được phân loại theo 3 nhóm tiêu chí chính: nhóm $A$ (nhóm tiêu chí về trình độ); nhóm $B$ (nhóm tiêu chí về kinh nghiệm); nhóm $C$ (nhóm tiêu chí về năng lực chuyên môn). Đối với Tiêu chí 4 về phẩm chất đạo đức là điều kiện cần hay còn gọi là tiêu chuẩn để được xét/xếp hạng chuyên gia do vậy không đưa vào tính điểm. Như vậy, với bài viết này, chúng tôi đã đạt được mục tiêu trong việc làm rõ khái niệm về chuyên gia $\mathrm{KH \& CN}$ ngành TNMT và giới thiệu về tiêu chí xác định, lựa chọn chuyên gia $\mathrm{KH \& CN}$ trong các lĩnh vực TN\&MT.O

\section{Tài liệu tham khảo}

[1]. Luật KH\&CN 2013.

[2]. Nghị định số 36/2017/NĐ-CP ngày 04 tháng 4 năm 2017 của Thủ tướng Chính phủ quy định chức năng, nhiệm vụ, quyền hạn và cơ cấu tổ chức của Bộ Tài nguyên và Môi trường;

[3]. Đại Từ điển tiếng Việt/Trung tâm Ngôn ngữ và Văn hóa Việt Nam. NXB: Văn hóa - Thông tin, 1999.

[4]. Bách khoa toàn thư mở Wikipedia.

[5]. Lê Xuân Định/Khung cấu trúc và tiêu chí dữ liệu CSDL chuyên gia KH\&CN quốc tế. Báo cáo tham luận tại Hội thảo chuyên đề nội dung 2 thuộc đề tài $K H \& C N$ cấp nhà nước mã số KX06.02/11-15.

[6]. National institute of Food and Agriculture, 2012. http://www.csrees.usda.gov/

[7]. Natural sciences and Engineering Research Council of Canada, 2012.

[8]. Chinese Academy of Sciences: Institute of Policy and Management, 2012.O

\section{Summary}

The proposal of concept and criteria for determining scientific and technological experts in the field of natural resources and environment

Nguyen Manh Dung, Luu Thi Thuy Ngoc, Institute of Geodesy and Catography

Truong Thi Hoa, Department of Science and Technology, Ministry of Natural Resources and Environment

"The fundamental of developing the system of criterial for determining scientific and technological (S\&T) experts and personnel in the field of natural resources and environment" is an Institution-level research implemented by the Vietnam Institute of Geodesy and Cartography. The objective of the research is (1) to clarify the rationale; and (2) to develop a set of indicators for determination, selection of S\&T experts in the field of natural resources and environment. One of the most important research goal is to give a definition of the words "expert", "S\&T expert" and provide the criteria considering a S\&T expert. Another problem is the shortage in human resources database in order to provide quickly and accurately the expert information to serve the selection procedure of Ministerial-level research. Within the confines of a journal article, wehereby onlypresent some main results of the research, which provides basic concept and definition, and the most general criteria for the selection for S\&T expert within the scope of natural resources and environment field. 